OPEN ACCESS

Edited by:

Changiz Geula,

Northwestern University,

United States

Reviewed by: Sebastian Palmqvist, Lund University, Sweden

Mirjana Babić Leko,

University of Split, Croatia

*Correspondence:

Taher Darreh-Shor taher.darreh-shori@ki.se

Received: 03 May 2021

Accepted: 21 July 2021

Published: 26 August 2021

Citation:

Karami A, Darreh-Shori T, Schultzberg $M$ and Eriksdotter $M$ (2021) CSF and Plasma Cholinergic Markers in Patients With Cognitive

Impairment

Front. Aging Neurosci. 13:704583. doi: 10.3389/fnagi.2021.704583

\section{CSF and Plasma Cholinergic Markers in Patients With Cognitive Impairment}

\author{
Azadeh Karami ${ }^{1}$, Taher Darreh-Shori ${ }^{1 *}$, Marianne Schultzberg ${ }^{2}$ and Maria Eriksdotter ${ }^{1,3}$ \\ ${ }^{1}$ Division of Clinical Geriatrics, Department of Neurobiology, Care Sciences and Society, Center for Alzheimer Research, \\ Karolinska Institutet, Campus Flemingsberg, Stockholm, Sweden, ${ }^{2}$ Division of Neurogeriatrics, Department of Neurobiology, \\ Care Sciences and Society, Center for Alzheimer Research, Karolinska Institutet, Campus Solna, Stockholm, Sweden, \\ ${ }^{3}$ Theme Inflammation and Aging, Karolinska University Hospital, Stockholm, Sweden
}

Introduction: Alzheimer's disease (AD) is the most prevalent form of dementia with symptoms of deteriorating cognitive functions and memory loss, partially as a result of a decrease in cholinergic neurotransmission. The disease is incurable and treatment with cholinesterase inhibitors (ChEls) is symptomatic. Choline acetyltransferase (ChAT), the enzyme that synthesizes acetylcholine (ACh), has been proven recently to be present in both cerebrospinal fluid (CSF) and plasma. As ChAT plays a role in regulating the extracellular ACh levels, it may have an impact on prognosis and cognitive performance in $\mathrm{AD}$ patients.

Objectives: To measure ChAT activity and its protein concentration in CSF and plasma from patients with $A D$, mild cognitive impairment $(\mathrm{MCl})$, or Subjective cognitive impairment (SCI).

Methods: Plasma and CSF samples were obtained from $21 \mathrm{AD}, 32 \mathrm{MCl}$, and $30 \mathrm{SCl}$ patients. The activity and protein levels of ChAT and acetylcholinesterase (AChE), the enzyme catalyzing the hydrolysis of ACh, were analyzed using an integrated activity and protein concentration ELISA-like assay. A Cholinergic Index was calculated as the ratio of ChAT to AChE activities in CSF. The data were analyzed in relation to dementia biomarkers and cognitive performance of the patients.

Results: The CSF ChAT activity was significantly higher (55-67\%) in $\mathrm{MCl}$ patients compared to AD and SCl cases. The CSF Cholinergic Index was 41 and 22\% lower in $\mathrm{AD}$ patients than in $\mathrm{MCl}$ and $\mathrm{SCl}$ subjects, respectively. This index correlated positively with the $A \beta_{42} / p$-tau ratio in CSF in SCl but negatively with that in $A D$ and $M C l$. The ChAT activity and protein levels in plasma exhibited significant differences with the pattern of $\mathrm{AD}>>\mathrm{MCl}>\mathrm{SCl}$.

Conclusion: This is the first study investigating soluble levels of the key cholinergic enzyme, ChAT, in both plasma and CSF of individuals at different clinical stages of 
dementia. Although further validation is needed, the overall pattern of the results suggests that in the continuum of $A D$, the cholinergic signaling exhibits an inverse $U$-shape dynamic of changes in the brain that greatly differs from the changes observed in the plasma compartment.

Keywords: Alzheimer's disease (AD), choline acetyltransferase (ChAT), acetylcholinesterase (AChE), amyloid beta $(\mathrm{A} \beta)$, Cholinergic Index, mild cognitive impairment (MCI), subjective cognitive impairment (SCl), tau protein

\section{INTRODUCTION}

Neurodegenerative diseases leading to dementia are common and have major clinical and socioeconomic consequences. According to the World Health Organization (WHO), there are currently about 50 million patients with dementia forecasted to increase to 150 million in 2050 (World Health Organization, 2019). The most common dementia disorder is Alzheimer's disease $(\mathrm{AD})$, representing about $60 \%$. $\mathrm{AD}$ is a progressive and incurable disorder with a successive decline in cognitive functions (Bartus, 2000). Cholinergic neurons in the basal forebrain are particularly liable to the AD-related pathological changes, and the degeneration of these neurons, projecting to the cerebral cortex and hippocampus, is associated with memory problems in $\mathrm{AD}$ (Bartus, 2000; Mufson et al., 2008).

About 90 percent of non-excitable cells in the brain are cholinoceptive and sensitive to changes in extracellular acetylcholine (ACh) levels (Vijayaraghavan et al., 2013), the neurotransmitter that is the primary signaling molecule of cholinergic neurons and that stimulates a diverse array of muscarinic and nicotinic receptors. ACh is synthesized by the enzyme choline acetyltransferase (ChAT) in the cytosol of cholinergic nerve terminals, stored in synaptic vesicles and released via exocytosis into the synaptic cleft.

In contrast to most other small-molecule neurotransmitters, the post-synaptic activity of $\mathrm{ACh}$ is not terminated through its reuptake but by two powerful hydrolytic enzymes, acetylcholinesterase (AChE) and butyrylcholinesterase (BuChE). These enzymes are concentrated in the synaptic cleft, ensuring a rapid decrease in ACh concentration after its release from the pre-synaptic terminal. Under normal conditions, the levels of $\mathrm{ACh}$ are regulated through the net result of synthesis by ChAT and degradation by $\mathrm{AChE}$ and BuChE to maintain a certain level or duration of action of free ACh in the system. This regulation is suggested to be disturbed in $\mathrm{AD}$ through two mechanisms i.e., decreased activity of ChAT, and/or increased activity of $\mathrm{AChE}$ and BuChE, both of which lead to a low concentration and reduced turnover of $\mathrm{ACh}$ in the cholinergic system (Perry et al., 1978; Atack et al., 1986; Giacobini et al., 1989; DeKosky et al., 1992). Early findings of the loss of cholinergic neurons and marked reduction in $\mathrm{ACh}$ in $\mathrm{AD}$ led to the subsequent development of the first drugs available for pharmacological treatment of $\mathrm{AD}$, the cholinesterase inhibitors (ChEIs) such as donepezil, rivastigmine and galantamine.

Alzheimer's disease pathology is also characterized by intracellular neurofibrillary tangles (NFT) and extracellular plaques of aggregated amyloid beta $(A \beta)$ peptide which accumulate in vulnerable brain regions (Sennvik et al., 2000) and both $\mathrm{AChE}$ and BuChE have been found aggregated in the amyloid plaques along with A $\beta$ (Darreh-Shori et al., 2009a,b). It has also been shown that, in the presence of excess apolipoprotein $\mathrm{E}$ (ApoE), $\mathrm{A} \beta$ interacts with these enzymes and forms highly stable BuChE/AChE-A $\beta$-ApoE complexes (BA $\beta A C$ ), strongly associated with AD pathology (Darreh-Shori et al., 2011a,b, 2012). Formation of these complexes have also been found to act as a switch for the hyperactivation of BuChE and AChE with rapid lowering of ACh levels (Darreh-Shori et al., 2009a,b).

We have reported evidence for the presence of ChAT in human extracellular fluids (Vijayaraghavan et al., 2013) and shown that treatment with galantamine in $\mathrm{AD}$ patients resulted in changes in ChAT and AChE in cerebrospinal fluid (CSF) compared with placebo (Karami et al., 2019). Moreover, ADpatients treated with cells releasing nerve growth factor (NGF) in the basal forebrain (Eriksdotter-Jönhagen et al., 2012) also showed changes in the CSF levels of ChAT and AChE (Karami et al., 2015). However, there is still a lack of knowledge on the levels of the key cholinergic enzymes ChAT and AChE in CSF and plasma in untreated patients with $\mathrm{AD}$ and in individuals with mild cognitive impairment (MCI) or subjective cognitive impairment (SCI).

The purpose of this study was to investigate possible differences in the cholinergic markers in CSF and plasma from persons with SCI, MCI, or AD, and the relation to cognition and levels of CSF AD biomarkers.

\section{MATERIALS AND METHODS}

\section{Subjects}

The study population consisted of referrals to the Memory Clinic at Karolinska University Hospital, Huddinge, Sweden, between 2007 and 2009, who were diagnosed with SCI, MCI, or AD. All subjects were thoroughly investigated for memory complaints in the memory clinic. SCI was defined as the presence of cognitive complaints in the absence of pathological neuropsychological testing (Reisberg and Gauthier, 2008; Reisberg et al., 2008). Thus, although the subjects with SCI did not exhibit objective signs of cognitive impairment after extensive clinical and technical workup and were considered clinically cognitively healthy, they should not be referred to as healthy controls. The $\mathrm{AD}$ diagnosis was defined according to the International Classification of Disease 10th revision (ICD-10) criteria (World Health Organization, 1992). The MCI diagnosis was established according to the Winblad criteria (Winblad et al., 2004). The diagnoses for AD, MCI, and SCI were done by a thorough diagnostic workup according to the clinical routine at the Memory clinic, Karolinska University Hospital, including medical history, history from a 
proxy and clinical examination (in particular, neurological and psychiatric assessments) and cognitive assessment with minimental state examination (MMSE). Additionally, evaluation with brain imaging [MRI or computerized tomography (CT)], blood tests and dementia biomarkers in CSF as well as a neuropsychological test battery were performed. The diagnosis was then set at a diagnosis conference with specialists attending.

The inclusion criteria were: (i) lumbar puncture performed as part of the clinical work-up, (ii) diagnosis of $\mathrm{AD}, \mathrm{MCI}$, or SCI. Exclusion criteria were: (i) somatic or psychiatric disease significantly affecting cognitive performance, (ii) dementia due to dementia disorders other than $\mathrm{AD}$, and (iii) first-degree relative with $\mathrm{AD}$ among the SCI subjects.

All patients and their caregivers provided written informed consent to participate in the study, which was conducted according to the Declaration of Helsinki and subsequent revisions. The regional Ethics Committee in Stockholm County, Sweden approved the study.

\section{Clinical Assessment and Sample Collection}

The subjects underwent a thorough routine work-up at the Memory Clinic, Karolinska University Hospital, Huddinge. Following medical history, history from a proxy and clinical examination including neurological and psychiatric assessment, cognitive screening was performed according to the MMSE test (Folstein et al., 1975). In addition, an extensive cognitive test battery and an MRI scan of the brain were performed.

Plasma samples were collected for routine analyses and cholinergic markers (see below). Lumbar puncture was performed in a standardized manner with the patient in a sitting position between 8 and 12 a.m. to avoid bias by possible circadian fluctuation of CSF biomarkers. The tap was performed with a non-traumatic cannula placed in the intervertebral space L3/L4 or L4/L5. All CSF and plasma samples were aliquoted at the time of collection in polypropylene tubes of 0.5 or $1 \mathrm{ml}$ and were kept stored at $-80^{\circ} \mathrm{C}$ (Darreh-Shori et al., 2004; Vijayaraghavan et al., 2013) until further analysis of the $\mathrm{AD}$ biomarkers $\mathrm{A} \beta 42$, total tau (t-tau) and phosphorylated tau at threonine 181 (p-tau181, henceforth called p-tau in the main text), and cholinergic markers (see below). CSF and plasma samples were obtained from 21 patients with $\mathrm{AD}, 32$ with MCI, and 30 with SCI.

\section{Analysis of CSF and Plasma Cholinergic Markers}

Choline acetyltransferase activity in CSF samples was analyzed by a colorimetric assay described previously (Vijayaraghavan et al., 2013). A modified version of the assay protocol was used, which sequentially quantified both the enzyme activity and the amount of ChAT protein, as well as the endogenous choline levels. For the activity measurement, undiluted CSF or $400 \times$ dilution of plasma samples was used. For measuring ChAT levels in plasma, one of the plasma aliquots was used to prepare the $400 \times$ diluted plasma samples. All samples were handled and processed together in the same manner. The dilution buffer for the plasma samples was
TBS-TX [10 mM Tris-buffered saline (TBS), pH 7.4, containing $0.05 \%$ Triton X-100 and 1.0 mM EDTA].

High-binding 384-well microtiter plates (Nunc MaxiSorp, Denmark) were pre-coated at $4^{\circ} \mathrm{C}$ with $75 \mu \mathrm{L} /$ well of a ChAT antibody (MAB 3447; R\&D System; reconstituted at a concentration of $250 \mu \mathrm{g} / \mathrm{mL}$ ) and incubation overnight. The working solution of this antibody was prepared at $1 \mu \mathrm{g} / \mathrm{mL}$ in carbonate coating buffer, $\mathrm{pH}$ 9.0. After the incubation, the plate was washed once with $100 \mu \mathrm{L} /$ well TBS buffer $(10 \mathrm{mM}$, $\mathrm{pH}$ 7.4). Then the antibody-coated wells were incubated with $10 \mu \mathrm{L} /$ well in triplicates of the samples or a 2 -fold serial dilution of a ChAT protein-calibrated pooled plasma standards (ranging from 1.2 to $0.019 \mu \mathrm{g} / \mathrm{mL}$, prepared in TBS-TX. On a set of wells on the plate that were not coated with the primary antibody, $50 \mu \mathrm{L} /$ well of a 2 -fold serial dilution of choline chloride standards (ranging from 50 to $0.78 \mu \mathrm{M}$ in TBS-TX) were added. All samples and the ChAT-calibrated plasma standards were applied both as native (unmodified) samples and as denatured (by heating in a thermal cycler $3 \times 8 \mathrm{~min}$ at $98^{\circ} \mathrm{C}$ ). The denatured samples served as controls for both the ChAT activity and the endogenous concentration of choline in the samples. Then, to all wells, except for the choline standards, $40 \mu \mathrm{L} /$ well of Cocktail A was added and incubated with for $2 \mathrm{~h}$ at $38^{\circ} \mathrm{C}$, under constant gentle shaking. The Cocktail A was prepared in TBS-TX, containing $62.5 \mu \mathrm{M}$ of acetyl-coenzyme A (ACoA), $1.25 \mathrm{U} / \mathrm{ml}$ of phosphotransacetylase, $8.75 \mathrm{mM}$ of lithium potassium acetyl-phosphate, $6.25 \mu \mathrm{M}$ choline chloride and $0.75 \mathrm{mM}$ of eserine hemisulfate. After the incubation, the plate was placed on ice for $\sim 2 \mathrm{~min}$ and centrifuged at $1500 \mathrm{rpm}$ for $1 \mathrm{~min}$ to recover the condensed volume. Then the sealing tape was removed and $25 \mu \mathrm{L} /$ well of Cocktail B was added to all wells including those with choline standards. The Cocktail B was prepared in $50 \mathrm{mM} \mathrm{K}^{+}$ $\mathrm{Na}^{+}$phosphate buffer, $\mathrm{pH} 7.6$, containing $0.93 \mathrm{U} / \mathrm{ml}$ of choline oxidase, 1/5000 Streptavidin-HRP, $3.0 \mathrm{mM}$ 4-aminoantipyrine and $6.3 \mathrm{mM}$ phenol. The plate was immediately placed in a microplate spectrophotometer reader (Tecan Infinite M1000) and changes in absorbance at $500 \mathrm{~nm}$ was monitored at $3 \mathrm{~min}$ intervals, enabling assessment of choline concentration using the choline standards.

Choline acetyltransferase activity ( $\mathrm{nmol} / \mathrm{min} / \mathrm{mL}$ samples) was calculated based on the difference between the choline concentration (in pmol) in the denatured and native samples, divided by incubation time (in $\min$ ) at $38^{\circ} \mathrm{C}$ and volume (in $\mathrm{mL}$ ) of the samples.

Following reading, the plate was sealed and incubated at $4^{\circ} \mathrm{C}$ overnight. The plate was then emptied and washed once for $5 \mathrm{~min}$ with TBS, then blocked with $100 \mu \mathrm{L} /$ well of blocking solution (the coating buffer, containing $5 \% \mathrm{w} / \mathrm{v}$ bovine serum albumin) for $1-2 \mathrm{~h}$ at room temperature (RT) under gentle orbital shaking. After $3 \times 5$ min washing with TBS-T (TBS, containing $0.05 \%$ Tween 20), the plate was incubated first for $60 \mathrm{~min}$ at $38^{\circ} \mathrm{C}$ with $50 \mu \mathrm{L} /$ well of detecting antibody solution (anti-ChAT rabbit polyclonal antibody, PAB14536, Abnova, diluted 1/3500). Subsequently, $25 \mu \mathrm{L} /$ well of a secondary antibody solution (alkaline phosphatase-conjugated polyclonal Swine anti-rabbit antibody, Dako, diluted 1/1700) was added to the wells and 
incubated for an additional $30 \mathrm{~min}$. Both antibody solutions were prepared in TBS-T, containing $1 \%$ BSA and $0.01 \% \mathrm{NaN}_{3}$. After washing and addition of a substrate solution (10 $\mathrm{mM}$ di-sodium p-nitrophenyl phosphate in $1.0 \mathrm{M}$ diethanolamine buffer, $\mathrm{pH}$ 9.8, containing $1 \mathrm{M} \mathrm{MgCl}$ and $0.01 \% \mathrm{NaN}_{3}$ ), the reaction was monitored at $405 \mathrm{~nm}$ wavelength using an Infinite ${ }^{\circledR}$ M1000 Tecan microplate reader (Vijayaraghavan et al., 2013).

The activity of AChE was assessed by the modified Ellman's colorimetric assay described in Darreh-Shori et al. (2008). The corresponding levels of AChE protein in the samples were measured by integrating the activity assay with functional ELISA setup, which measures the protein levels of the functionally intact enzyme, as described in Darreh-Shori et al. (2008). The activity and protein levels of AChE were determined in $5 \times$ pre-diluted (in TBS-TX) samples.

\section{CSF Cholinergic Index and the Functional Activities of Cholinergic Markers in CSF and Plasma}

To estimate the functional ChAT activity in CSF $\left(\mathrm{ChAT}_{\mathrm{F}}\right)$, the overall ChAT activity (in $\mathrm{pmol} / \mathrm{min} / \mathrm{mL}$ ) was divided to its protein in CSF (in $\mathrm{ng} / \mathrm{mL}$ ). A similar calculation was used to estimate the functional activity of CSF AChE $\left(\mathrm{AChE}_{\mathrm{F}}\right)$. The recently reported Cholinergic Index in CSF, obtained by dividing the functional levels of CSF ChAT (in $\mathrm{pmol} / \mathrm{min} / \mu \mathrm{g}$ ) to $\mathrm{CSF} \mathrm{AChE}$ (in $\mathrm{nmol} / \mathrm{min} / \mu \mathrm{g}$ ) (Karami et al., 2019). Thus, an increase in this Cholinergic Index $\left(\mathrm{ChAT}_{\mathrm{F}} / \mathrm{AChE}_{\mathrm{F}}\right.$ activities) indicates a net increase in CSF ACh levels.

\section{Analysis of AD Biomarkers}

Analysis of $A \beta_{42}$ peptide, t-tau and p-tau in CSF samples was performed with xMAP technology using the Inno-Bia AlzBio 3 kit (Innogenetics, Gent, Belgium) as described previously (Olsson et al., 2005). We also calculated the CSF ratio $A \beta_{42} / \mathrm{p}$ tau, which is a commonly used ratio in $\mathrm{AD}$ diagnostic work-up (Duits et al., 2014; Lehmann et al., 2015; Palmqvist et al., 2015; Marizzoni et al., 2019).

\section{Statistical Analysis}

Analysis of variance (ANOVA) test was used to evaluate the differences between the groups when the data fulfilled the normal distribution criteria. In ambiguous cases, the data were transformed using natural logarithm. The significant level was set to $p<0.05$. A significant ANOVA was followed by Fisher's PLSD post hoc test. Data in the form of ratios or percentages were analyzed with a non-parametric test (Kruskal-Wallis instead of ANOVA), followed by Mann-Whitney $U$ test as post hoc analysis. Correlation analyses were performed using Pearson correlation analysis and were visualized using simple regression plots. When deemed necessary the correlations were validated using the non-parametric Spearman rank correlation test. All raw data are presented in the table as mean $\pm \mathrm{SD}$ values, whereas in the text and figures the data are presented as mean \pm S.E.M.

\section{RESULTS}

\section{Demographic and Clinical Characteristics at Baseline}

In total, samples and data from 83 (47 women and 36 men) patients with memory impairment were included with a mean age of $71( \pm 1.1)$ years and a mean MMSE total score of $26.9( \pm 0.3)$ with scores between 17 and 30. The demographic data and levels of cholinergic and AD biomarkers in CSF and plasma are shown in Table 1.

\section{CSF ChAT}

The activity of ChAT in CSF was significantly higher in the MCI group, i.e., $55 \pm 17 \%$ higher than in the AD group $(p<0.039)$ and $67 \pm 11 \%$ higher than the SCI group $(p<0.0016$, Figure 1A). The CSF levels of ChAT protein did not show any significant differences between the groups (Figure 1B). The CSF $\mathrm{ChAT}_{\mathrm{F}}$ (i.e., ratio between ChAT activity and ChAT protein concentration in CSF) was significantly higher in MCI patients compared to SCI subjects ( $53 \pm 11 \%, p<0.0083)$. There was a significant negative correlation between CSF ChAT activity and its protein concentration in the AD group $(r=-0.47$, $p<0.043$, Figure 1C), but not among the other groups or the overall subjects.

TABLE 1 | Demographic data overview and measured levels of relevant biomarkers in CSF and plasma.

\begin{tabular}{|c|c|c|c|c|}
\hline & $A D$ & $M C I$ & SCI & Total \\
\hline $\mathrm{N}$ (women/men) & $21(7 / 14)$ & $32(19 / 13)$ & $30(21 / 9)$ & $83(47 / 36)$ \\
\hline Age in years & $77 \pm 10$ & $73 \pm 9$ & $66 \pm 8$ & $72 \pm 10$ \\
\hline MMSE score & $24 \pm 3$ & $27 \pm 3$ & $29 \pm 2$ & $27 \pm 3$ \\
\hline $\operatorname{CSF} A \beta_{42}(p g / m l)$ & $519 \pm 186$ & $665 \pm 298$ & $900 \pm 274$ & $713 \pm 303$ \\
\hline CSF p-tau (pg/ml) & $107 \pm 43$ & $59 \pm 22$ & $49 \pm 18$ & $68 \pm 36$ \\
\hline CSF t-tau (pg/ml) & $712 \pm 371$ & $316 \pm 140$ & $213 \pm 79$ & $379 \pm 289$ \\
\hline $\mathrm{A} \beta_{42} / \mathrm{p}$-tau181 & $6 \pm 5$ & $14 \pm 9$ & $22 \pm 12$ & $15 \pm 11$ \\
\hline $\begin{array}{l}\text { CSF AChE activity } \\
(\mathrm{nmol} / \mathrm{min} / \mathrm{ml})\end{array}$ & $12 \pm 4$ & $10 \pm 4$ & $10 \pm 4$ & $11 \pm 4$ \\
\hline $\begin{array}{l}\text { CSF AChE protein } \\
(\mathrm{ng} / \mathrm{ml})\end{array}$ & $48 \pm 21$ & $46 \pm 24$ & $53 \pm 27$ & $49 \pm 24$ \\
\hline $\begin{array}{l}\text { CSF ChAT activity } \\
(\mathrm{nmol} / \mathrm{min} / \mathrm{ml})\end{array}$ & $1.5 \pm 1.1$ & $2.2 \pm 1.2$ & $1.3 \pm 0.8$ & $1.7 \pm 1.1$ \\
\hline $\begin{array}{l}\text { CSF ChAT protein } \\
\text { concentration } \\
(\mu \mathrm{g} / \mathrm{ml})\end{array}$ & $1.0 \pm 0.8$ & $0.8 \pm 0.3$ & $0.8 \pm 0.3$ & $0.9 \pm 0.5$ \\
\hline $\begin{array}{l}\text { Plasma ChAT } \\
\text { activity } \\
(\mathrm{nmol} / \mathrm{min} / \mathrm{ml})\end{array}$ & $117 \pm 60$ & $82 \pm 81$ & $62 \pm 63$ & $83 \pm 73$ \\
\hline $\begin{array}{l}\text { Plasma ChAT } \\
\text { protein } \\
\text { concentration } \\
(\mu \mathrm{g} / \mathrm{ml})\end{array}$ & $150 \pm 83$ & $64 \pm 45$ & $44 \pm 24$ & $75 \pm 63$ \\
\hline
\end{tabular}

The values are means \pm standard deviation. $A \beta_{42}$, beta-amyloid peptide 1-42; AChE, acetylcholinesterase; AD, Alzheimer's disease; ChAT, choline acetyltransferase; CSF, cerebrospinal fluid; MCl, mild cognitive impairment; MMSE, mini-mental state examination; p-tau181, phosphorylated tau 181; SCI, subjective cognitive impairment; $t$-tau, total tau. 

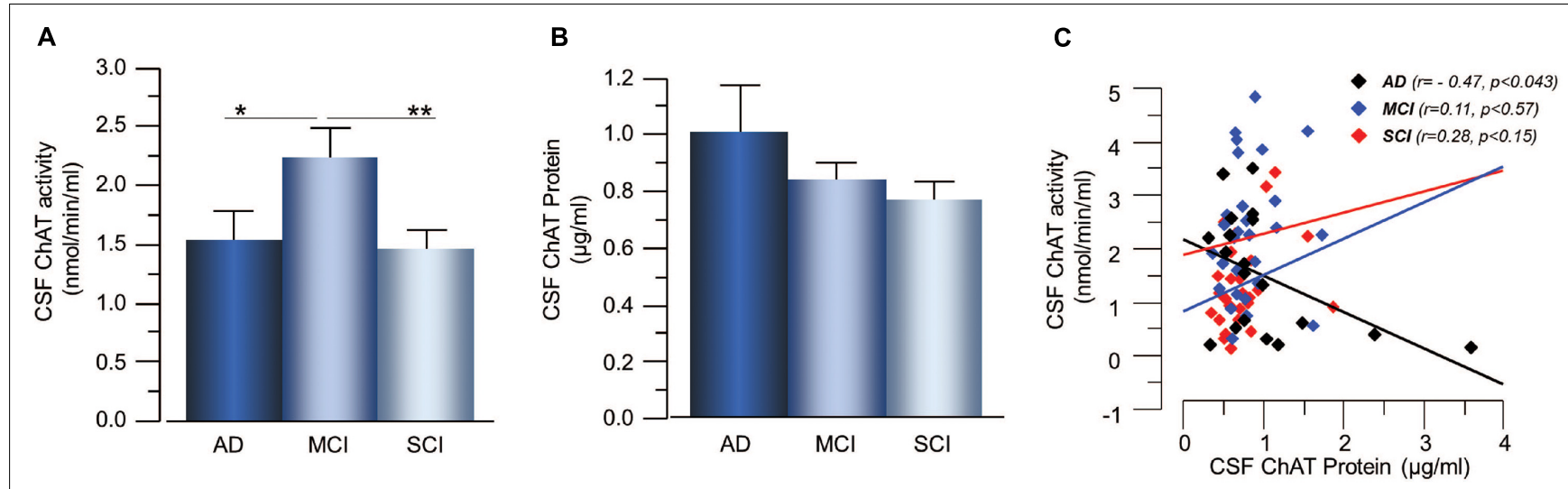

FIGURE 1 | Changes in ChAT levels in CSF of patients in different stages of dementia. (A) CSF ChAT activity was higher in patients with the clinical diagnosis of MCl than in AD or SCl. (B) The corresponding ChAT protein concentrations in CSF did not show any significant differences. (C) The activity and protein concentration of ChAT in CSF exhibited negative correlation mainly in the AD group. AChE = acetylcholinesterase; AD = Alzheimer's disease; ChAT = choline acetyltransferase; $\mathrm{CSF}=$ cerebrospinal fluid; $\mathrm{MCl}=$ mild cognitive impairment; $\mathrm{SCl}=$ subjective cognitive impairment. ${ }^{\star} p<0.05,{ }^{\star *} p<0.01$.

\section{Plasma ChAT}

The plasma ChAT activity was higher in the AD patients, i.e., $57 \pm 28 \%$ higher than the MCI-group $(p<0.071)$ and $90 \pm 26 \%$ higher than the SCI-group $(p<0.024$, Figure 2A). The plasma ChAT protein concentration was significantly higher in the $\mathrm{AD}$ patients, i.e., by $198 \pm 22 \%$ compared to the MCIgroup $(p<0.0006)$ and $245 \pm 14 \%$ higher than the SCI-group $\left(p<0.0001\right.$, Figure 2B). The $\mathrm{ChAT}_{\mathrm{F}}$ in plasma did not differ significantly between the groups. The plasma ChAT activity was positively correlated to the ChAT protein concentration in all groups $(r=0.72, p<0.0001)$ as well as within each group $(p<0.003$ for $\mathrm{AD}, p<0.0001$ for MCI and $p<0.0009$ for SCI, Figure 2C). No correlation was found between CSF ChAT activity or protein levels and the plasma ChAT activity $(p<0.88)$ or protein levels $(p<0.49)$.

\section{CSF AChE}

The activity and protein concentration of the ACh-degrading enzyme, AChE, in CSF did not show any significant differences between the groups (Figures $\mathbf{3 A}, \mathbf{B}$ ). In order to estimate changes in the level of functional $\mathrm{AChE}$ activity $\left(\mathrm{AChE}_{\mathrm{F}}\right)$, the ratio between AChE activity to AChE protein levels in CSF were calculated. The $\mathrm{AChE}_{\mathrm{F}}$ in CSF did not differ between the groups. There was significant correlation between the AChE activity and protein concentration in CSF in all groups $(r=0.46, p<0.0001)$ as well as within each group (Figure 3C).

\section{The CSF Cholinergic Index}

Cholinergic signaling is most likely regulated through a balance between synthesis, release and degradation of ACh. We hence defined a CSF Cholinergic Index as the ratio between the functional ChAT (in $\mathrm{nmol} / \mathrm{min} / \mu \mathrm{g}$ ) and that of functional AChE (in $\mathrm{nmol} / \mathrm{min} / \mu \mathrm{g}$ ) in $\mathrm{CSF}\left(\mathrm{ChAT}_{\mathrm{F}} / \mathrm{AChE}_{\mathrm{F}}\right)$. Thus, an increase in this ratio means a net increase in ACh levels. The CSF Cholinergic Index was significantly higher in the MCI group than in the AD patients $(41 \pm 9 \% p<0.048$, Figure $4 \mathrm{~A})$, but not compared to the SCI group $(19 \pm 9 \% p<0.21)$. The Cholinergic
Index did not show a statistically significant difference but was just numerically higher in SCI compared to AD (22 $\pm 12 \%$ $p<0.32)$.

\section{Correlations to Cognition}

As expected, lower MMSE scores as well as lower levels of $\mathrm{A} \beta_{42}$ and higher levels of $\mathrm{t}$-tau and $\mathrm{p}$-tau in the CSF were found in patients with $\mathrm{AD}$ as compared to patients with MCI and SCI (Figure $4 \mathbf{B}$ ). The CSF $\mathrm{A} \beta_{42} / \mathrm{p}$-tau ratio was significantly lower in AD patients compared to $\mathrm{MCI}(34 \pm 5 \%$, $p<0.001)$ and SCI $(72 \pm 10 \%, p<0.0001)$, and in MCI patients compared to SCI subjects $(38 \pm 7 \%, p<0.0032$, Figure 4C). There was a positive correlation between MMSE test scores and the CSF A $\beta_{42} / \mathrm{p}$-tau ratio for all cases $(r=0.31$ $p<0.005)$.

Furthermore, MMSE scores correlated negatively to the levels of t-tau $(r=-0.39, p<0.0002)$ and $\mathrm{p}$-tau $(r=-0.40, p<0.0001)$ and positively to the levels of $\mathrm{A}_{42}(r=0.23, p<0.04)$ in CSF as analyzed in all subjects together (no correlations were found within each group).

Analysis of the correlation between cognition and the CSF Cholinergic Index showed no significant correlation.

Mini-mental state examination scores correlated negatively to the plasma ChAT activity $(r=-0.31, n=48, p<0.04$, Figure 5A) and to the plasma ChAT protein for all cases $(r=-0.45, n=48$, $p<0.001$, Figure 5B). Subgroup analyses indicated that the correlation remained significant only among the MCI patients $(r=-0.53, n=22, p<0.009)$.

\section{Correlations Between Cholinergic Markers and AD Biomarkers}

The CSF Cholinergic Index correlated positively with the $A \beta_{42} / \mathrm{p}$ tau ratio in the SCI group $(r=0.44, p<0.031$, Figure $4 \mathrm{D})$, but negatively with the $\mathrm{A} \beta_{42} / \mathrm{p}$-tau ratio in the $\mathrm{AD}$ group $(r=-0.39$, $p<0.097)$.

The CSF Cholinergic Index correlated negatively with the p-tau levels in SCI group $(r=-0.50, p<0.015)$, but not in the 

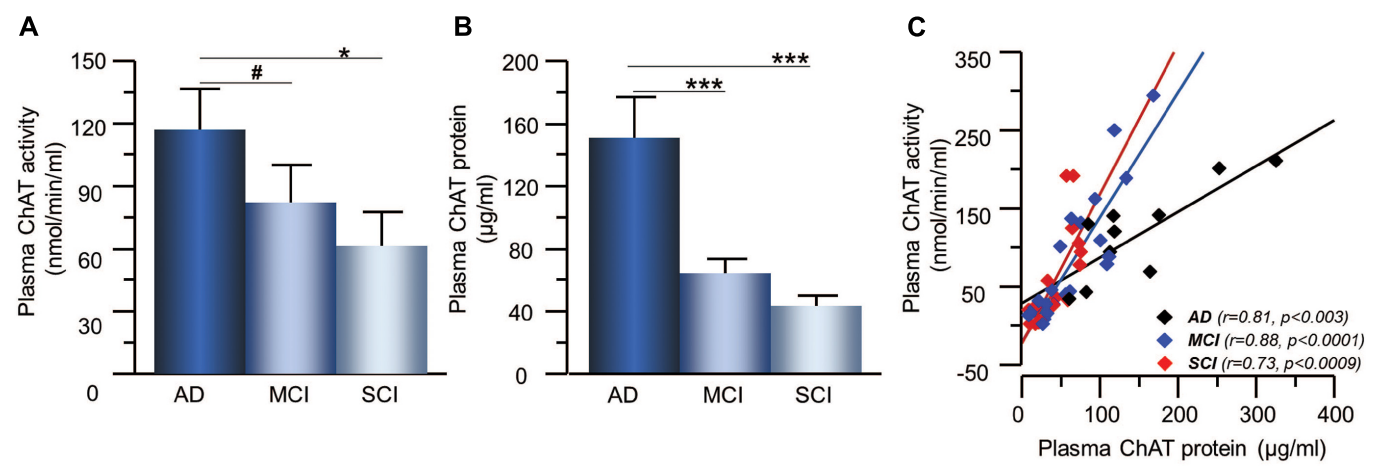

FIGURE 2 | Changes in ChAT levels in plasma of patients in different stages of dementia. (A) The plasma ChAT activity was higher in AD compared to patients with a clinical diagnosis of $\mathrm{MCl}$ or SCl. (B) A similar pattern of differences was found with regard to ChAT protein levels in plasma in the three groups. (C) Plasma ChAT activity correlated with its protein concentration in all three groups. $\mathrm{AD}=$ Alzheimer's disease; ChAT = choline acetyltransferase; $\mathrm{MCl}=$ mild cognitive impairment; $\mathrm{SCl}=$ subjective cognitive impairment. ${ }^{*} p<0.05,{ }^{* \star *} p<0.001,{ }^{\#} p<0.07$.
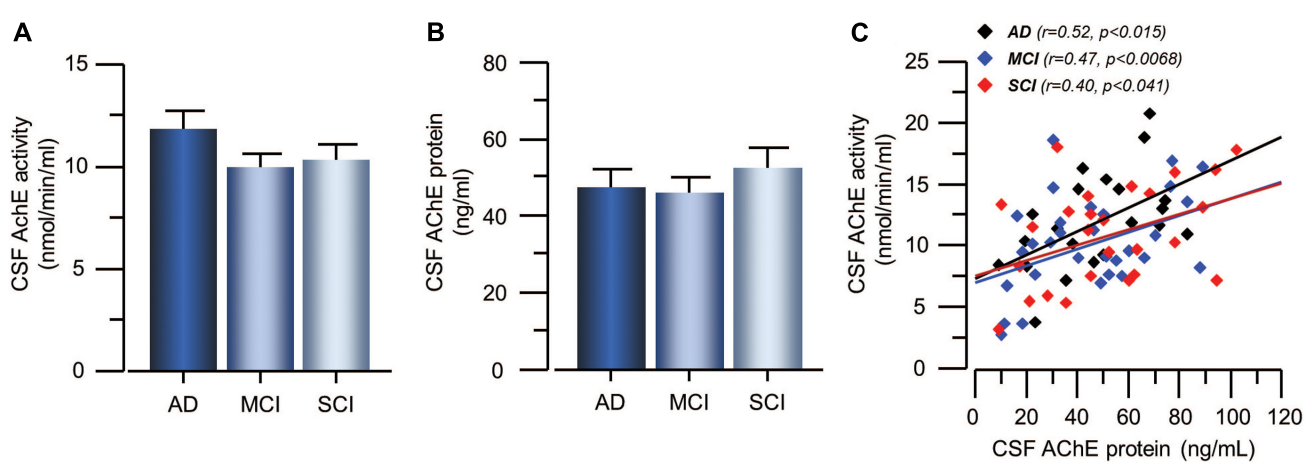

FIGURE 3 | Activity and protein levels of AChE in CSF of the patients. (A) The CSF AChE activity did not differ between patients with the clinical diagnoses of AD, $\mathrm{MCl}$, or SCl. (B) Similarly, the CSF protein levels of AChE did not differ between the groups. (C) The overall AChE activity correlated with its protein levels in the CSF. $\mathrm{AChE}$ = acetylcholinesterase; $\mathrm{AD}$ = Alzheimer's disease; CSF = cerebrospinal fluid; $\mathrm{MCl}$ = mild cognitive impairment; SCl = subjective cognitive impairment.
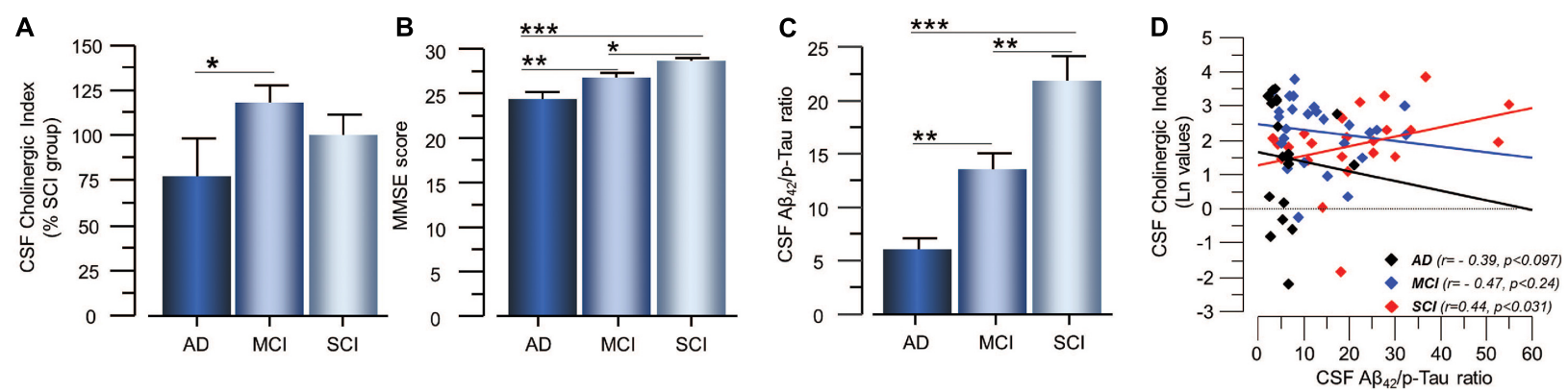

FIGURE 4 | Estimated Cholinergic Index in CSF of patients in different stages of dementia and its relation to cognition and the CSF A $\beta_{42} / \mathrm{p}$-tau ratio. (A) The estimated CSF Cholinergic index (ChAT $/ A C h E_{F}$ ) was highest in the MCl group. (B) The global cognitive performance of the patients as assessed by MMSE test shows the expected pattern. (C) The CSF A $\beta_{42} / p$-tau ratio also follows the expected pattern of lowest in AD and highest in SCl. (D) The CSF Cholinergic index showed differential correlation with the CSF A $\beta_{42} / \mathrm{p}$-tau ratio in SCl and AD. In panel (D), the CSF Cholinergic index is given in natural logarithm (Ln). The CSF Cholinergic index is defined as a ratio between the functional levels of ChAT (in nmol $/ \mathrm{min} / \mu \mathrm{g}$ ) and the functional levels of AChE (in nmol/min $/ \mu \mathrm{g}$ ) in CSF (i.e., $\mathrm{ChAT}_{\mathrm{F}} / \mathrm{ACh} \mathrm{E}_{\mathrm{F}}$ activities). $\mathrm{AChE}=$ acetylcholinesterase; $\mathrm{AD}=$ Alzheimer's disease; ChAT = choline acetyltransferase; $\mathrm{CSF}=$ cerebrospinal fluid; $\mathrm{MCl}=$ mild cognitive impairment; $\mathrm{p}$-tau $=$ phosphorylated tau $181 . \mathrm{SCl}=$ subjective cognitive impairment. ${ }^{*} p<0.05,{ }^{* *} p<0.01$, and ${ }^{* * *} p<0.001$.

$\mathrm{AD}(r=0.44, p<0.056)$ or MCI group $(r=0.17, p<0.40)$. The CSF Cholinergic Index did not correlate with the t-tau levels in any of the groups.
The plasma ChAT protein correlated positively with t-tau $(r=0.40, n=48, p<0.005$, Figure 5C) and p-tau $(r=0.31$, $n=48, p<0.03$, Figure 5D), but not with the CSF $\mathrm{A} \beta_{42}$ level 

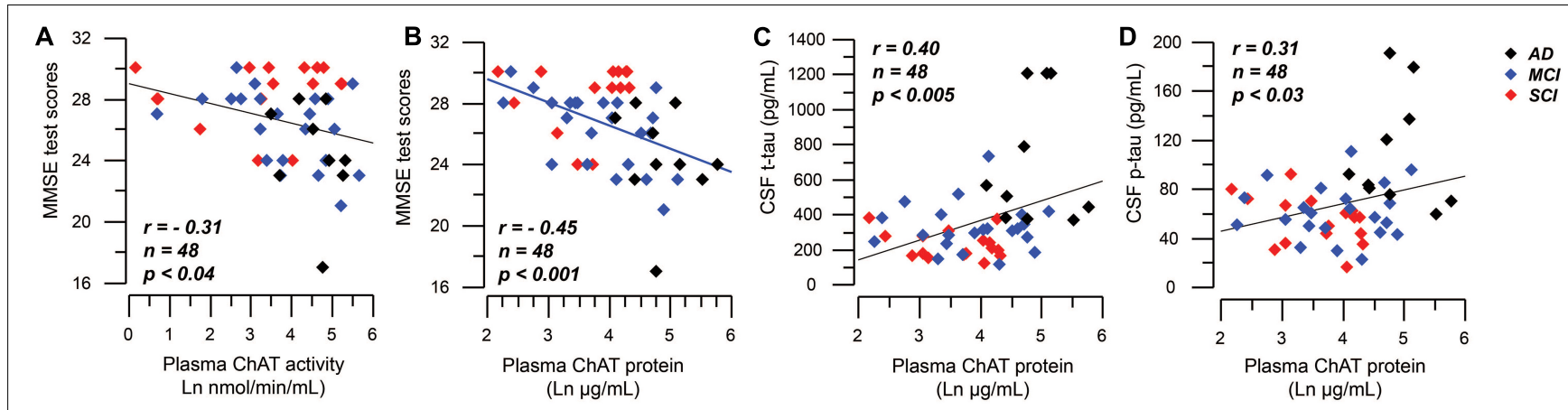

FIGURE 5 | Correlations between plasma ChAT levels and global cognition and CSF tau levels. (A) Illustrates a negative significant correlation between global cognitive performance as assessed by MMSE test and the activity of ChAT in plasma. Panel (B) shows the corresponding negative significant correlation between MMSE test scores and the plasma ChAT protein. Panels (C,D) show the positive correlations between the plasma ChAT protein and the t-tau (C) and p-tau (D) levels in CSF of all subjects. The plasma ChAT activity and protein levels are given in natural logarithm (Ln). AD = Alzheimer's disease; ChAT = choline acetyltransferase; $\mathrm{CSF}=$ cerebrospinal fluid; $\mathrm{MCl}=$ mild cognitive impairment; $\mathrm{p}$-tau = phosphorylated tau181 protein; $\mathrm{SCl}=$ subjective cognitive impairment; $\mathrm{t}$-tau = total tau protein.

as analyzed in all subjects together. Plasma ChAT activity did not correlate with these markers and no correlations were found within the subgroups.

Correlations were also found between the CSF AChE activity and the levels of CSF t-tau $(r=0.28, p<0.011$ in all patients, and $r=0.40, p<0.03$ in the SCI group) and CSF p-tau $(r=0.32$, $p<0.0033$ in all patients). The CSF AChE activity also correlated with the levels of CSF $\mathrm{A} \beta_{42}$, but only in the MCI group $(r=0.38$, $p<0.032$ ).

\section{Multivariate Logistic Regression Analysis of Cholinergic and AD Biomarkers}

To explore the relationship between cholinergic markers and the AD biomarkers, an exploratory analysis was done on subgroups which were positive or negative with regards to CSF levels of the $\mathrm{AD}$ biomarkers: $\mathrm{A} \beta_{42}+$ vs. $\mathrm{A} \beta_{42}-$ (cut-off $650 \mathrm{pg} / \mathrm{ml}$ ), t-tau + vs. t-tau- (cut-off $400 \mathrm{pg} / \mathrm{mL}$ ), or p-tau+ vs. p-tau(cut-off $78 \mathrm{pg} / \mathrm{mL}$ ). The results are presented in Supplementary Figures 1, 2. Briefly these analyses indicated that CSF ChAT activity (Supplementary Figure 1) and the CSF Cholinergic index (Supplementary Figure 2) in $\mathrm{A} \beta_{42}+$, $\mathrm{t}$-tau+, or $\mathrm{p}$-tau+ groups had very similar pattern to that observed in Figures 1, 4, respectively. This pattern was lost in $\mathrm{A} \beta_{42}-$, $\mathrm{t}$-tau-, or $\mathrm{p}$-taugroups indicating that these cholinergic markers were sensitive to the underlying pathological events in $\mathrm{AD}$.

To further explore the observations, multivariate logistic regression analysis was performed using diagnosis (SCI/MCI/AD) as the dependent variable and the cholinergic enzymes (activity and protein) levels and MMSE test score as the independent variables. This model predicted the diagnosis with 76, 61, and 53\% accuracy, respectively. A model that included only MMSE test score and the AD CSF biomarkers $\left(\mathrm{A} \beta_{42}\right.$, t-tau, and $\mathrm{p}$-tau) but not the cholinergic markers had a predictability of 70,72 , and $71 \%$ for the diagnoses of SCI, MCI, and $\mathrm{AD}$, respectively.

When the CSF levels of ChAT and AChE were included together with only MMSE and t-tau, the predictability of the model for SCI, MCI, and AD was 84, 75, and 79\%, respectively, which was superior to all models lacking the CSF cholinergic variables.

We also performed logistic regression analysis of the plasma ChAT activity and protein levels. A model that included the CSF $\mathrm{AD}$ biomarker $\left(\mathrm{A} \beta_{42}, \mathrm{t}\right.$-tau, and $\mathrm{p}$-tau $)$ and the plasma ChAT levels had a predictability of 88,87 , and $90 \%$ for the diagnoses of SCI, MCI, and AD, respectively. Without the plasma ChAT levels, the corresponding predictability was 77, 66, and 57\%. Additional inclusion of the MMSE test score did not improve the predictability of the model that included plasma ChAT levels (69, 82 , and $90 \%$, respectively).

\section{DISCUSSION}

The cholinergic hypothesis proposed the importance of cholinergic neuron degeneration in $\mathrm{AD}$ and that it was associated with cognitive impairment (Bartus et al., 1982). Since then, many studies have shown that the degeneration of the central cholinergic system is associated with cognitive decline (Drachman and Leavitt, 1974; Davies and Maloney, 1976; Mufson et al., 2008; Ballinger et al., 2016). However, less is known regarding the levels of the ACh-synthesizing enzyme ChAT and the ACh-degrading enzyme AChE in CSF and plasma in patients with cognitive impairment. The aim of the present study was to investigate these enzymes with regard to both their activity and protein level in relation to cognitive function and $\mathrm{AD}$ biomarkers. Comparison of data obtained from analysis of samples from patients with $\mathrm{AD}$ and MCI as well as individuals with SCI, showed significant differences between the groups and between the patterns in CSF and plasma.

The ChAT activity in CSF was higher in MCI patients compared to AD and SCI. This is in line with studies on the levels of ChAT activity in postmortem brain tissue (DeKosky et al., 2002; Ikonomovic et al., 2005). Thus, a difference in ChAT levels in CSF samples may serve to distinguish between clinical and preclinical forms of the disease. We have previously hypothesized that CSF ChAT activity and thereby extracellular ACh may be involved in the regulation of astroglial function in the brain 
(Malmsten et al., 2014). Furthermore, we found that astrocyte activity in the brain may follow an inverse U-shape dynamic in the continuum of $\mathrm{AD}$, with a peak at the MCI stage of the disease (Vijayaraghavan et al., 2013). Given that astrocytes constitute one of the sources of soluble ChAT in CSF (Vijayaraghavan et al., 2013; Darreh-Shori et al., 2014), the present finding that CSF ChAT levels were highest in the MCI group may suggest that CSF ChAT levels reflect an ongoing regulatory process, attempting to modulate a (protective or detrimental) functional status of astrocytes in the brain.

In two independent treatment studies in $\mathrm{AD}$ patients (one with encapsulated NGF-releasing cells and the other with a ChEI), we showed that CSF ChAT levels increased in response to the treatment and that the increase was positively correlated with measures of cognition (Karami et al., 2015, 2019). Three months treatment with the ChEI galantamine resulted in increased levels of ChAT activity in CSF (Karami et al., 2019). Encapsulated cells releasing NGF to the basal forebrain in ten $\mathrm{AD}$ patients with ongoing treatment with ChEIs resulted in increased levels of ChAT activity in CSF (Karami et al., 2015; Eyjolfsdottir et al., 2016). Thus, higher levels of ChAT activity in the CSF of MCI patients compared to AD patients would suggest that increased activation of extracellular ACh signaling is part of an intrinsic protective rather than detrimental mechanism, which when it fails to cope with the underlying disease processes, results in progress of MCI to AD.

We found a negative correlation between ChAT activity and ChAT protein levels in CSF samples from AD patients, but not in MCI and SCI. Reports indicate that ChAT activity is biologically and pathologically affected in the brain in several ways. One is phosphorylation and dephosphorylation by kinases and phosphatases, which increases and respectively decreases ChAT activity (Dobransky et al., 2000). Another is inhibition by some endogenous molecules which seem to be accumulated in the AD brain (Andriamampandry and Kanfer, 1993). Unpublished data in our laboratory further evince that ChAT is extremely sensitive to oxidative environment, rendering ChAT protein inactive which can be prevented or reversed by a reducing agent such as mercaptoethanol. Overall, the observed negative correlation between the enzyme activity and protein levels of ChAT may suggest that higher ChAT protein levels in CSF of $\mathrm{AD}$ patients is a sign of an unsuccessful compensatory mechanism to recover the reduced ACh in synapses, and/or to dampen hyperactivity of astroglial cells (Darreh-Shori et al., 2013; Vijayaraghavan et al., 2013).

In plasma, both the activity and protein levels of ChAT differed between $\mathrm{AD}, \mathrm{MCI}$, and SCI patients, according to the pattern of $\mathrm{AD}>>\mathrm{MCI}>\mathrm{SCI}$. This pattern between the groups was completely different from that seen in CSF and may indicate that extracellular cholinergic signaling in the periphery may increase during the disease progression of $\mathrm{AD}$. In addition, both activity and protein levels of ChAT in plasma correlated negatively with global cognition as assessed by the MMSE test. Plasma levels of ChAT protein also correlated with the CSF $\mathrm{t}$-tau and p-tau levels. Indeed, multivariate logistic regression analysis indicated that a model, which included plasma ChAT activity and protein levels had superior diagnostic predictability than a model that included only CSF AD biomarkers $(88 \%$ vs. $71 \%$ overall correct classification). Overall, the pattern of these observations suggested that elevated plasma levels of ChAT protein were related to a more severe stage of the disease as could be deduced by the global cognitive performance and levels of the $\mathrm{AD}$ biomarkers, $\mathrm{A} \beta_{42}$, t-tau, and p-tau in CSF.

Many studies report the involvement of neuroinflammation and its fundamental role in the progression of the neuropathological changes that are observed in AD. There is ample evidence for the presence of immune-related proteins and cells within close proximity to amyloid plaques in $\mathrm{AD}$ (Rogers et al., 1988; Griffin et al., 1989). ACh is important for peripheral functions and cholinergic signals also regulate innate and adaptive immune functions (Shaked et al., 2009; RosasBallina et al., 2011). It has been shown that ACh suppresses or modulates the immune responses to inflammatory cues (RosasBallina and Tracey, 2009). We have shown that, in addition to lymphocytes, both astrocytes and human embryonic stem cells can express and release ChAT into the culture medium in response to inflammatory stimuli (Vijayaraghavan et al., 2013; Malmsten et al., 2014). Given that AD is developed gradually within a time span of 2-3 decades, the observed pattern of ChAT levels in plasma may indicate that at least some of the driving factors of $\mathrm{AD}$ originate in the periphery rather than in the brain itself. This is particularly appreciated from the finding that ChAT levels in CSF did not differ between AD and SCI groups. Indeed, in a previous report we showed a close cross-talk between the cytokine levels in plasma and CSF as a function of plasma and CSF BuChE activity, but not AChE activity (Darreh-Shori et al., 2013). In plasma, the levels of soluble ChAT and BuChE are much higher than the levels of AChE (Vijayaraghavan et al., 2013). The plasma ChAT and BuChE activity also seem to be closely linked to each other to such a degree that e.g., the levels of ChAT protein in plasma are altered in subjects carrying a genetic variant of $\mathrm{BuChE}$ that has $30 \%$ reduction of the activity (Vijayaraghavan et al., 2013).

The CSF AChE activity did not differ between the three groups. Nonetheless, it correlated positively in all patients with the t-tau and p-tau levels. A similar finding was reported earlier (Johansson et al., 2013). AChE activity in CSF also correlated with CSF $A \beta_{42}$ levels, but only in the MCI group. Currently, it is not known why the levels of $\mathrm{AChE}$ and tau protein correlate or what this association signifies. AChE is normally anchored within the synaptic cleft of the cholinergic neuronal interfaces. Given that increased tau levels in CSF may reflect ongoing synaptic and/or neuronal degeneration and given that cholinergic neurons are heavily affected by $\mathrm{AD}$, the positive relationship between $\mathrm{AChE}$ and tau may reflect the ongoing synaptic degeneration in the brain.

The CSF Cholinergic Index was highest in patients at very mild stage of dementia. It also correlated positively with the $\mathrm{A} \beta_{42} / \mathrm{p}$-tau ratio in the SCI group but negatively in the $\mathrm{AD}$ group. This may reflect the results of continuous ongoing insults on the cholinergic system in the brain, which predict inverse U-shape dynamic changes in the central cholinergic signaling in the course of dementia. This supports that changes in the central cholinergic system may play a crucial role in the underlying pathological events in dementia. Indeed, numerous pharmacoepidemiological reports suggest that undermining the 
proper cholinergic signaling by drugs with anti-cholinergic burden not merely induce symptoms of dementia but may in fact increase the future incidence of dementia (Jessen et al., 2010; Akter et al., 2015; Gomm et al., 2016; Chuang et al., 2017; Richardson et al., 2018; Coupland et al., 2019; Kumar A. et al., 2020; Kumar R. et al., 2020). Overall, these findings imply that treatment with ChEIs may be most effective if started early in asymptomatic patients as a preventive measure as is the case for cardiovascular disorders by treatment of high blood pressure or high cholesterol levels.

A limitation in this study is the known heterogeneity of the MCI and SCI groups which may have included pre-clinical AD patients. Nonetheless, samples were obtained from patients investigated according to clinical routine in a memory clinic, where they were clinically diagnosed as AD, MCI, or SCI. Another limitation is that the number of subjects was relatively small and thereby the study should be considered as a pilot study.

In conclusion, the present study showed that levels of both ChAT enzyme activity and ChAT protein in CSF and plasma samples differed between $\mathrm{AD}, \mathrm{MCI}$, and SCI patients. The finding that plasma levels of ChAT activity were significantly higher in AD than in SCI, whereas in CSF, the ChAT activity levels were higher in MCI patients, is interesting. This may indicate that ChAT activity is correlated with the progression of the disease. A decrease in CSF ChAT activity could predict the transition from $\mathrm{MCI}$ to $\mathrm{AD}$. An opposite pattern was found in plasma, where increasing ChAT levels seem to follow the clinical pattern of the disease, i.e., from SCI to MCI to AD. This is particularly important since plasma sampling is a simple procedure compared to lumbar puncture to obtain CSF. However, our findings need to be confirmed in a larger cohort of $\mathrm{AD}$ and pre-clinical individuals. The inverse U-shape changes in the CSF Cholinergic Index suggested that cholinergic deficit can be regarded as a crucial player and not a bystander of the disease. This in turn emphasizes the need for research on whether early treatment with ChEIs represents an effective preventive measure against development of dementia disorders.

\section{DATA AVAILABILITY STATEMENT}

The original contributions presented in the study are included in the article/Supplementary Material, further inquiries can be directed to the corresponding author/s.

\section{ETHICS STATEMENT}

The studies involving human participants were reviewed and approved by The Regional Ethics Committee in Stockholm County. The patients/participants provided their written informed consent to participate in this study.

\section{AUTHOR CONTRIBUTIONS}

AK performed the analyses and wrote the first draft. TD-S and AK revised the first draft and prepared the figures and tables.
TD-S, MS, and ME revised the manuscript to the final draft for submission. All authors contributed to the article and approved the submitted version.

\section{FUNDING}

This work was supported by funds from The Swedish Research Council (2016-02317 and 2014-3876), The Swedish Brain Foundation (Hjärnfonden), Karolinska Institutet Research Funds, Stiftelsen för Gamla Tjänarinnor, Demensfonden, Åhlén Foundation, Magnus Bergvalls Foundation, Anér Foundation, Gun and Bertil Stohnes Foundation, Olle Engkvist Foundation, and The Regional Agreement on Medical Training and Clinical Research (ALF) between Stockholm County Council, and Karolinska Institutet.

\section{SUPPLEMENTARY MATERIAL}

The Supplementary Material for this article can be found online at: https://www.frontiersin.org/articles/10.3389/fnagi.2021. 704583/full\#supplementary-material

Supplementary Figure $\mathbf{1}$ | Cerebrospinal fluid (CSF) ChAT activity in patients stratified based on cut-off levels of CSF AD biomarkers. Panel (A) shows CSF ChAT activity in patients with clinical diagnosis of $\mathrm{AD}, \mathrm{MCl}$, and $\mathrm{SCl}$. The left panel represents cases who had CSF $A \beta$ levels lower than the cut-off value of $650 \mathrm{pg} / \mathrm{ml}$ $\left(A \beta+\right.$ group). The right panel represent cases with CSF $A \beta_{42}$ levels greater than the cut-off value (A $\beta$ - group). Panel $(\mathbf{B})$ shows the corresponding stratification based on CSF total tau levels. The left panel represents cases with CSF t-tau levels greater than the cut-off value of $400 \mathrm{pg} / \mathrm{ml}$ (Tau+ group), while the right panel are cases with CSF t-tau levels lower than the cut-off value (Tau-group). $\mathrm{NA}=$ not available, indicating that none of the SCI patients had CSF t-tau levels greater than the cut-off value. Panel (C) shows the corresponding stratification based on CSF levels of phosphorylated tau ( $p$-tau). The left panel represents cases with CSF $p$-tau levels greater than the cut-off value of $78 \mathrm{ng} / \mathrm{ml}(\mathrm{p}$-tau+ group), while the right panel are cases with CSF p-tau levels lower than the cut-off value ( $p$-tau-group). These analyses should be considered with caution due to the small numbers of subjects. AD = Alzheimer's disease; ChAT = choline acetyltransferase; CSF = cerebrospinal fluid; $\mathrm{MCl}$ = mild cognitive impairment; $\mathrm{p}$-tau = phosphorylated tau181 protein; $\mathrm{SCl}=$ subjective cognitive impairment; t-tau $=$ total tau protein. ${ }^{*} p<0.05$, and ${ }^{* *} p<0.01$. The $p$-values are not adjusted for multiple comparisons.

Supplementary Figure 2 | Cerebrospinal fluid (CSF) Cholinergic Index in patients stratified based on cut-off levels of CSF AD biomarkers. Panel (A) shows the CSF Cholinergic Index in patients with clinical diagnoses of $\mathrm{AD}, \mathrm{MCl}$, and $\mathrm{SCl}$. The left panel represents cases who had CSF A $\beta$ levels lower than the cut-off value of $650 \mathrm{pg} / \mathrm{ml}(A \beta+$ group). The right panel represent cases with CSF A 42 levels greater than the cut-off value (A $\beta$ - group). Panel $(\mathbf{B})$ shows the corresponding stratification based on CSF total tau levels. The left panel represents cases with CSF t-tau levels greater than the cut-off value of $400 \mathrm{pg} / \mathrm{ml}$ (Tau+ group), while the right panel are cases with CSF t-tau levels lower than the cut-off value (Taugroup). NA = not available, indicating that none of the SCI patients had CSF t-tau levels greater than the cut-off value. Panel (C) shows the corresponding stratification based on CSF levels of phosphorylated tau ( $p$-tau). The left panel represents cases with CSF $p$-tau levels greater than the cut-off value of $78 \mathrm{ng} / \mathrm{ml}$ (p-tau+ group), while the right panel are cases with CSF $p$-tau levels lower than the cut-off value ( $p$-tau-group). These analyses should be considered with caution due to the small numbers of subjects. $A D=$ Alzheimer's disease; ChAT = choline acetyltransferase $;$ CSF = cerebrospinal fluid; $\mathrm{MCl}=$ mild cognitive impairment; $\mathrm{p}$-tau = phosphorylated tau181 protein; $\mathrm{SCl}=$ subjective cognitive impairment; $\mathrm{t}$-tau $=$ total tau protein. ${ }^{*} p<0.05$, and $\# p<0.09$. The $p$-values are not adjusted for multiple comparisons. The Cholinergic Index was calculated as described in section "Materials and Methods." 


\section{REFERENCES}

Akter, S., Hassan, M. R., Shahriar, M., Akter, N., Abbas, M. G., and Bhuiyan, M. A. (2015). Cognitive impact after short-term exposure to different proton pump inhibitors: assessment using CANTAB software. Alzheimers Res. Ther. 7:79.

Andriamampandry, C., and Kanfer, J. N. (1993). Inhibition of cytosolic human forebrain choline acetyltransferase activity by phospho-L-serine: a phosphomonoester that accumulates during early stages of Alzheimer's disease. Neurobiol. Aging 14, 367-372. doi: 10.1016/0197-4580(93)90123-s

Atack, J. R., Perry, E. K., Bonham, J. R., Candy, J. M., and Perry, R. H. (1986). Molecular forms of acetylcholinesterase and butyrylcholinesterase in the aged human central nervous system. J. Neurochem. 47, 263-277. doi: 10.1111/j.14714159.1986.tb02858.x

Ballinger, E. C., Ananth, M., Talmage, D. A., and Role, L. W. (2016). Basal forebrain cholinergic circuits and signaling in cognition and cognitive decline. Neuron 91, 1199-1218. doi: 10.1016/j.neuron.2016.09.006

Bartus, R. T. (2000). On neurodegenerative diseases, models, and treatment strategies: lessons learned and lessons forgotten a generation following the cholinergic hypothesis. Exp. Neurol. 163, 495-529. doi: 10.1006/exnr.2000.7397

Bartus, R. T., Dean, R. R., Beer, B., and Lippa, A. S. (1982). The cholinergic hypothesis of geriatric memory dysfunction. Science 217, 408-414. doi: 10.1126/ science.7046051

Chuang, Y. F., Elango, P., Gonzalez, C. E., and Thambisetty, M. (2017). Midlife anticholinergic drug use, risk of Alzheimer's disease, and brain atrophy in community-dwelling older adults. Alzheimer's Dement. 3, 471-479. doi: 10. 1016/j.trci.2017.06.004

Coupland, C. A. C., Hill, T., Dening, T., Morriss, R., Moore, M., and HippisleyCox, J. (2019). Anticholinergic Drug Exposure and the Risk of Dementia: A Nested Case-Control Study. JAMA Internal Med. 179, 1084-1093. doi: 10.1001/ jamainternmed.2019.0677

Darreh-Shori, T., Forsberg, A., Modiri, N., Andreasen, N., Blennow, K., Kamil, C., et al. (2011a). Differential levels of apolipoprotein E and butyrylcholinesterase show strong association with pathological signs of Alzheimer's disease in the brain in vivo. Neurobiol. Aging 32 2320, e15-e32.

Darreh-Shori, T., Hellström-Lindahl, E., Flores-Flores, C., Guan, Z., Soreq, H., and Nordberg, A. (2004). Long-lasting acetylcholinesterase splice variations in anticholinesterase-treated Alzheimer's disease patients. J. Neurochem. 88, 1102-1113. doi: 10.1046/j.1471-4159.2003.02230.x

Darreh-Shori, T., Hosseini, S. M., and Nordberg, A. (2014). Pharmacodynamics of Cholinesterase Inhibitors Suggests Add-on Therapy with a Low-Dose Carbamylating Inhibitor in Patients on Long-Term Treatment with Rapidly Reversible Inhibitors. J. Alzheimer's Dis. 39, 423-440. doi: 10.3233/jad-130845

Darreh-Shori, T., Kadir, A., Almkvist, O., Grut, M., Wall, A., Blomquist, G., et al. (2008). Inhibition of acetylcholinesterase in CSF versus brain assessed by ${ }^{11}$ C-PMP PET in AD patients treated with galantamine. Neurobiol. Aging 29, 168-184. doi: 10.1016/j.neurobiolaging.2006.09.020

Darreh-Shori, T., Modiri, N., and Nordberg, A. (2009a). Apolipoprotein E and Butyrylcholinesterase synergistically promote $\mathrm{Ab}$ peptides oligomerization. Alzheimer's \& Dementia. J. Alzheimer's Associat. 5:225.

Darreh-Shori, T., Modiri, N., and Nordberg, A. (2009b). ApoE and amyloid beta deflate the cholinergic neurotransmission by boosting the activity and stability of cholinesterases in the brain. Alzheimer's Dement. J. Alzheimer's Associat. 5:305.

Darreh-Shori, T., Modiri, N., Blennow, K., Baza, S., Kamil, C., Ahmed, H., et al. (2011b). The apolipoprotein E epsilon4 allele plays pathological roles in AD through high protein expression and interaction with butyrylcholinesterase. Neurobiol. Aging 32, 1236-1248. doi: 10.1016/j.neurobiolaging.2009.07.015

Darreh-Shori, T., Siawesh, M., Mousavi, M., Andreasen, N., and Nordberg, A. (2012). Apolipoprotein epsilon4 Modulates Phenotype of Butyrylcholinesterase in CSF of Patients with Alzheimer's Disease. J. Alzheimer's Dis. 28, 443-458. doi: 10.3233/jad-2011-111088

Darreh-Shori, T., Vijayaraghavan, S., Aeinehband, S., Piehl, F., Lindblom, R. P., Nilsson, B., et al. (2013). Functional variability in butyrylcholinesterase activity regulates intrathecal cytokine and astroglial biomarker profiles in patients with Alzheimer's disease. Neurobiol. Aging 34, 2465-2481. doi: 10.1016/j. neurobiolaging.2013.04.027

Davies, P., and Maloney, A. (1976). Selective loss of central cholinergic neurons in Alzheimer's disease. Lancet 308:1403. doi: 10.1016/s0140-6736(76)91936-X
DeKosky, D. S. T., Harbaugh, R. E., Schmitt, F. A., Bakay, R. A., Chui, H. C., Knopman, D. S., et al. (1992). Cortical biopsy in Alzheimer's disease: diagnostic accuracy and neurochemical, neuropathological, and cognitive correlations. Ann. Neurol. 32, 625-632. doi: 10.1002/ana.410320505

DeKosky, S. T., Ikonomovic, M. D., Styren, S. D., Beckett, L., Wisniewski, S., Bennett, D. A., et al. (2002). Upregulation of choline acetyltransferase activity in hippocampus and frontal cortex of elderly subjects with mild cognitive impairment. Ann. Neurol. 51, 145-155. doi: 10.1002/ana.10069

Dobransky, T., Davis, W. L., Xiao, G. H., and Rylett, R. J. (2000). Expression, purification and characterization of recombinant human choline acetyltransferase: phosphorylation of the enzyme regulates catalytic activity. Biochem. J. 349, 141-151. doi: 10.1042/bj3490141

Drachman, D. A., and Leavitt, J. (1974). Human memory and the cholinergic system: a relationship to aging? Archiv. Neurol. 30, 113-121. doi: 10.1001/ archneur.1974.00490320001001

Duits, F. H., Teunissen, C. E., Bouwman, F. H., Visser, P. J., Mattsson, N., Zetterberg, H., et al. (2014). The cerebrospinal fluid "Alzheimer profile": easily said, but what does it mean? Alzheimer's Dementia 10, 713.-723.

Eriksdotter-Jönhagen, M., Linderoth, B., Lind, G., Aladellie, L., Almkvist, O., Andreasen, N., et al. (2012). Encapsulated cell biodelivery of nerve growth factor to the basal forebrain in patients with Alzheimer's disease. Dement. Geriat. Cognit. Disord. 33, 18-28. doi: 10.1159/000336051

Eyjolfsdottir, H., Eriksdotter, M., Linderoth, B., Lind, G., Juliusson, B., Kusk, P., et al. (2016). Targeted delivery of nerve growth factor to the cholinergic basal forebrain of Alzheimer's disease patients: application of a second-generation encapsulated cell biodelivery device. Alzheimer's Res. Therapy 8:30.

Folstein, M. F., Folstein, S. E., and McHugh, P. R. (1975). "Mini-mental state". A practical method for grading the cognitive state of patients for the clinician. J. Psychiatr. Res. 12, 189-198.

Giacobini, E., DeSarno, P., Clark, B., and McIlhany, M. (1989). The cholinergic receptor system of the human brain: neurochemical and pharmacological aspects in aging and Alzheimer. Prog. Brain Res. 79, 335-343. doi: 10.1016/ s0079-6123(08)62493-0

Gomm, W., von Holt, K., Thome, F., Broich, K., Maier, W., Fink, A., et al. (2016). Association of Proton Pump Inhibitors With Risk of Dementia: A Pharmacoepidemiological Claims Data Analysis. JAMA Neurol. 73, 410-416. doi: 10.1001/jamaneurol.2015.4791

Griffin, W., Stanley, L., Ling, C., White, L., MacLeod, V., Perrot, L., et al. (1989). Brain interleukin 1 and S-100 immunoreactivity are elevated in Down syndrome and Alzheimer disease. Proc. Natl. Acad. Sci. 86, 7611-7615. doi: 10.1073/pnas.86.19.7611

Ikonomovic, M. D., Mufson, E. J., Wuu, J., Bennett, D. A., and DeKosky, S. T. (2005). Reduction of choline acetyltransferase activity in primary visual cortex in mild to moderate Alzheimer's disease. Archiv. Neurol. 62, 425-430. doi: 10.1001/archneur.62.3.425

Jessen, F., Kaduszkiewicz, H., Daerr, M., Bickel, H., Pentzek, M., Riedel-Heller, S., et al. (2010). Anticholinergic drug use and risk for dementia: target for dementia prevention. Eur. Arch. Psychiat. Clin. Neurosci. 260 Suppl 2, S111-S115.

Johansson, P., Almqvist, E. G., Johansson, J. O., Mattsson, N., Andreasson, U., Hansson, O., et al. (2013). Cerebrospinal fluid (CSF) 25-hydroxyvitamin D concentration and CSF acetylcholinesterase activity are reduced in patients with Alzheimer's disease. PLoS One 8:e81989. doi: 10.1371/journal.pone.0081989

Karami, A., Eriksdotter, M., Kadir, A., Almkvist, O., Nordberg, A., and DarrehShori, T. (2019). CSF Cholinergic index, a new biomeasure of treatment effect in patients with Alzheimer's disease. Front. Mol. Neurosci. 12:239. doi: 10.3389/ fnmol.2019.00239

Karami, A., Eyjolfsdottir, H., Vijayaraghavan, S., Lind, G., Almqvist, P., Kadir, A., et al. (2015). Changes in CSF cholinergic biomarkers in response to cell therapy with NGF in patients with Alzheimer's disease. Alzheimer Dis. Associat. Disord. $11,1316-1328$.

Kumar, A., Kumar, R., Flanagan, J., Langstrom, B., Bjorndahl, L., and DarrehShori, T. (2020). Esomeprazole reduces sperm motility index by targeting the spermic cholinergic machinery: A mechanistic study for the association between use of proton pump inhibitors and reduced sperm motility index. Biochem. Pharmacol. 182:114212. doi: 10.1016/j.bcp.2020.114212

Kumar, R., Kumar, A., Nordberg, A., Langstrom, B., and Darreh-Shori, T. (2020). Proton pump inhibitors act with unprecedented potencies as inhibitors of the acetylcholine biosynthesizing enzyme-A plausible missing link for their 
association with incidence of dementia. Alzheimer's \& Dement. J. Alzheimer's Associat. 16, 1031-1042. doi: 10.1002/alz.12113

Lehmann, S., Gabelle, A., and Paquet, C. (2015). Can we rely only on ratios of cerebrospinal fluid biomarkers for AD biological diagnosis? Alzheimer's \& Dement. J. Alzheimer's Associat. 11, 1125-1126. doi: 10.1016/j.jalz.2014.09.003

Malmsten, L., Vijayaraghavan, S., Hovatta, O., Marutle, A., and Darreh-Shori, T. (2014). Fibrillar $\beta$-amyloid 1-42 alters cytokine secretion, cholinergic signalling and neuronal differentiation. J. Cell. Mol. Med. 18, 1874-1888. doi: 10.1111/ jcmm. 12343

Marizzoni, M., Ferrari, C., Babiloni, C., Albani, D., Barkhof, F., Cavaliere, L., et al. (2019). CSF cut-offs for MCI due to AD depend on APOE 4 carrier status. Neurobiol. Aging 89, 55-62. doi: 10.1016/j.neurobiolaging.2019.12.019

Mufson, E. J., Counts, S. E., Perez, S. E., and Ginsberg, S. D. (2008). Cholinergic system during the progression of Alzheimer's disease: therapeutic implications. Expert Rev. Neurotherapeut. 8, 1703-1718.

Olsson, A., Vanderstichele, H., Andreasen, N., De Meyer, G., Wallin, A., Holmberg, B., et al. (2005). Simultaneous measurement of \{beta\}-amyloid (1-42), total tau, and phosphorylated tau (Thr181) in cerebrospinal fluid by the xMAP technology. Clin. Chem. 51:336. doi: 10.1373/clinchem.2004.039347

Palmqvist, S., Zetterberg, H., Mattsson, N., Johansson, P., Minthon, L., Blennow, K., et al. (2015). Detailed comparison of amyloid PET and CSF biomarkers for identifying early Alzheimer disease. Neurology 85, 1240-1249. doi: 10.1212/wnl. 0000000000001991

Perry, E. K., Perry, R., Blessed, G., and Tomlinson, B. (1978). Changes in brain cholinesterases in senile dementia of Alzheimer type. Neuropathol. Appl. Neurobiol. 4, 273-277. doi: 10.1111/j.1365-2990.1978.tb00545.x

Reisberg, B., and Gauthier, S. (2008). Current evidence for subjective cognitive impairment (SCI) as the pre-mild cognitive impairment (MCI) stage of subsequently manifest Alzheimer's disease. Int. Psychogeriatr. 20, 1-16. doi: $10.1017 / \mathrm{s} 1041610207006412$

Reisberg, B., Prichep, L., Mosconi, L., John, E. R., Glodzik-Sobanska, L., Boksay, I., et al. (2008). The pre-mild cognitive impairment, subjective cognitive impairment stage of Alzheimer's disease. Alzheimer's \& Dement. J. Alzheimer's Associat. 4, S98-S108.

Richardson, K., Fox, C., Maidment, I., Steel, N., Loke, Y. K., Arthur, A., et al. (2018). Anticholinergic drugs and risk of dementia: case-control study. BMJ 361:k1315.

Rogers, J., Luber-Narod, J., Styren, S. D., and Civin, W. H. (1988). Expression of immune system-associated antigens by cells of the human central nervous system: relationship to the pathology of Alzheimer's disease. Neurobiol. Aging 9, 339-349. doi: 10.1016/s0197-4580(88)80079-4

Rosas-Ballina, M., and Tracey, K. (2009). Cholinergic control of inflammation. J. Internal Med. 265, 663-679. doi: 10.1111/j.1365-2796.2009.02098.x
Rosas-Ballina, M., Olofsson, P. S., Ochani, M., Valdés-Ferrer, S. I., Levine, Y. A., Reardon, C., et al. (2011). Acetylcholine-synthesizing T cells relay neural signals in a vagus nerve circuit. Science 334, 98-101. doi: 10.1126/science.1209985

Sennvik, K., Fastbom, J., Blomberg, M., Wahlund, L.-O., Winblad, B., and Benedikz, E. (2000). Levels of $\alpha$-and $\beta$-secretase cleaved amyloid precursor protein in the cerebrospinal fluid of Alzheimer's disease patients. Neurosci. Lett. 278, 169-172. doi: 10.1016/s0304-3940(99)00929-5

Shaked, I., Meerson, A., Wolf, Y., Avni, R., Greenberg, D., Gilboa-Geffen, A., et al. (2009). MicroRNA-132 potentiates cholinergic anti-inflammatory signaling by targeting acetylcholinesterase. Immunity 31, 965-973. doi: 10.1016/j.immuni. 2009.09.019

Vijayaraghavan, S., Karami, A., Aeinehband, S., Behbahani, H., Grandien, A., Nilsson, B., et al. (2013). Regulated Extracellular Choline Acetyltransferase Activity- The Plausible Missing Link of the Distant Action of Acetylcholine in the Cholinergic Anti-Inflammatory Pathway. PLoS One 8:e65936. doi: 10.1371/ journal.pone.0065936

Winblad, B., Palmer, K., Kivipelto, M., Jelic, V., Fratiglioni, L., Wahlund, L. O., et al. (2004). Mild cognitive impairment-beyond controversies, towards a consensus: report of the International Working Group on Mild Cognitive Impairment. J. Internal Med. 256, 240-246.

World Health Organization (2019). Dementia. Switzerland: World Health Organization.

World Health Organization (1992). International Classification of Disease 10th Revision (ICD-10). Geneva: World Health Organization.

Conflict of Interest: The authors declare that the research was conducted in the absence of any commercial or financial relationships that could be construed as a potential conflict of interest.

Publisher's Note: All claims expressed in this article are solely those of the authors and do not necessarily represent those of their affiliated organizations, or those of the publisher, the editors and the reviewers. Any product that may be evaluated in this article, or claim that may be made by its manufacturer, is not guaranteed or endorsed by the publisher.

Copyright (c) 2021 Karami, Darreh-Shori, Schultzberg and Eriksdotter. This is an open-access article distributed under the terms of the Creative Commons Attribution License (CC BY). The use, distribution or reproduction in other forums is permitted, provided the original author(s) and the copyright owner(s) are credited and that the original publication in this journal is cited, in accordance with accepted academic practice. No use, distribution or reproduction is permitted which does not comply with these terms. 